\title{
Parental Attitude towards the use of Contraceptives by Adolescents in Osogbo,Osun State.
}

\author{
Oyediran O.Olufemi, Faronbi Joel and Ajibade B.L
}

\begin{abstract}
Teenage pregnancy is an issue of concern in the world all over and it results from indiscriminate sex among the adolescents, this may not be unconnected to non usage of contraceptives by this age group due to the attitude of parents about it. Contraceptives are methods of preventing unwanted pregnancy among sexually active couples or adolescents and when effectively utilized, it promotes the health of family member and indirectly improving the health of the nation. The study assessed the parental knowledge about contraceptives, attitude of parents toward provision of contraceptives to adolescents and also found out the appropriate method that parents prefer for adolescents in Osogbo. The study adopted a descriptive design, 400 respondents were selected through a multi stage sampling technique from the two local governments in Osogbo. Data was collected using a validated structured questionnaire. Data was analyzed using descriptive and inferential Statistical Package for Social Sciences.

The result showed that more than half of the respondents (69.3\%) had good knowledge of contraception and $69.5 \%$ had negative attitude toward provision of contraceptives to adolescents. Also $57.0 \%$ of the respondents agreed that parent have influence on adolescent sexuality and contraception while high percentage of the respondents (84.2\%) agreed on total abstinence as the best contraception for adolescents. Statistical analysis further showed that there is a significant relationship between contraceptive device and adolescent sexuality, religion and gender. In conclusion, findings from this study revealed that parents had good knowledge about adolescents' contraception and they are in support of total abstinence as the best contraceptive option for adolescents. Therefore, there is need for educational programmes to improve on their attitudes toward all the methods of contraception, this will subsequently encourage them to allow their girls to use it.
\end{abstract}

Key words: Attitude, Parental, Adolescents, Contraceptives and Use.

\section{Introduction}

Teenage sexual activity is a worldwide issue and the age of initiation is rapidly decreasing. The consequences of sexual behaviour of teenagers are an enormous burden on themselves and society. These are due mainly to the little or no preparation and guidance they have on how to develop responsible sexual behaviour. Developmentally, adolescents reach physical maturity before they are cognitively able to appreciate the consequences of their behavour and their primary source of information regarding sexuality is their peer group. Most parents shy away from this responsibility. Many object to giving teenagers the capacity to delay parenthood while unsuccessfully imploring them to delay sexual activity. It has been found that withholding sex education and family planning services has not led to less teenage sexual activity in the United States, neither has the provision of needed information and services in Europe and Canada resulted in increased sexual activity, but it heightened sexual responsibility (Mboho, 2009)

Teenage pregnancy is one of the unfavorable and usually unplanned outcomes of adolescent sexual activity. According to Odujinrin (2007), about $20 \%$ of pregnant teenagers conceive during the first sexual exposure and 50\% within the first 6 months. The younger the age of initiating intercourse, the greater the likelihood of pregnancy. It has been documented that over half of the pregnancies in girls less than 16 years of age in Britain and America ended in induced abortion and those that continued had increased maternal and perinatal mortality (Ololade, 2008). Once a young woman becomes pregnant, whether the pregnancy is continued or not, the effects on her personal, social and educational life are often irreversible. In some societies, unmarried young women who become pregnant or who are known to have had an abortion may become social outcasts. Sometimes, young women are forced to give up school because of a fear that they will be a "bad influence" on other girls. Early parenthood, particularly for young women, may limit or preclude social, educational and employment development and the ability to achieve full status in society (UNFPA/WHO/UNICEF, 2005).

Despite campaign on the use of birth control devices, the use of contraceptives among unmarried adolescents is still low due to controversy among parents as to whether unmarried young adults should use contraceptives or not (Mboho, 2009). Forge (2003), pointed out that preventing unmarried young adults from using contraceptives does not reduce the number of adolescents having coitus but results in more unwanted pregnancies with the accompanied social, educational, economic and psychological effects. 
International Planned Parenthood Federation (IPPF) (2009) reported that a large number of adolescents whether in marriage or outside marriage in developed or developing countries are sexually active and must play safe sex using condom if they cannot abstain from sex. Ololade (2008) observed that adolescents are special group in our society who are still inadequately catered for in family planning services even when they are sexually active. The centre for disease control (CDC) and Reproductive health (2003) said that adolescents should be given support to make their own decisions about what is right for them, either to have sex or not to have.

\subsection{Statement of the Problem}

Teenage pregnancy among adolescents in Osogbo is on the increase with its various complications like septic abortion, child abandonment and sexually transmitted infections (Awodele 2008). This has been attributed to non usage of contraception among the sexually active age group adolescent. Effective use of contraceptive has been known to help in population control and reduction in adolescents' sexuality problems (World Health Organization 2004). The rate of child abandonment was very high in Osogbo as many abandoned children were displayed on screen virtually every day when the news was broadcast. Those that perpetuated the act were found most of the time to be secondary school girls. Therefore, this research work intends to explore the attitude of parents in Osogbo toward adolescent contraception.

\subsection{Research Questions.}

1. What is parental knowledge about contraceptives?

2. What is the parental attitude towards provision of contraceptives to adolescents?

3. Which methods of contraceptives do parents prefer for adolescents?

\subsection{Objectives of the Study}

1. To assess the knowledge of parents about contraceptives.

2. To assess parental attitude towards the provision of contraceptives to Adolescents.

3. To find out the appropriate method (s) of contraception that parents prefer for adolescents

Research Design: This is a descriptive cross sectional design to evaluate the attitude of parents toward the use of contraceptive by the adolescents. The design was adopted as the researcher would not manipulate any variable but would be discussed as occur in the research.

Research setting: This study was conducted in Osogbo, the capital of Osun state .It is located 9km north east of Ibadan, it covers an area of about 140 square $\mathrm{km}$ and lies at a height of $366 \mathrm{~m}$ above sea level. The population is about 288343 according to year 2006 population census. Osogbo has two local govts (Osogbo and Olorunda local governments) with their headquarters in Osogbo. Osogbo Local Government has 15 political wards while Olorunda Local Government has 11 political wards.Osogbo Local Government Area (LGA) is bounded in the north by Olorunda LGA, Egbedore LGA in the south and by Atakunmosa,Obokun and Boripe LGAs in the west. Its headquarter is located at Oke-Bale. Majority of Osogbo population are of Yoruba ethnic group. The religions practiced in Osogbo LGA include Christianity, Islam and Traditional religion.

\section{Study Population}

The study population was the parents of both sexes in selected areas in Osogbo Local Government and cut across all social strata, religious affiliation and marital status.

\section{Sampling Technique and Sample Size}

A multistage sampling technique was adopted to select participants in this study. The procedures were as follows, parents in Osogbo were clustered into two local governments and simple random sampling technique using ballot method was used to select Osogbo Local Government from the two local governments in Osogbo. The population of Osogbo local govt from 2006 census was 156,694. Two wards (Ataoja C ward 3 \&Alekuwodo ward 5) were also selected randomly using ballot method from the existing 15 wards in the selected local govt. There were about 200 buildings in each ward selected and systematic sampling technique was used to select 100 houses from each ward after determining the sampling interval by dividing the sampling frame (200 houses) by the sample size .The calculated sampling interval was used for each ward selected. In each house, two parents were randomly selected from each ward for questionnaires administration.200 parents were selected balloting from each ward. A total of 400 respondents were selected from the two wards.

The formula that was used for getting the sample size is Yamane's formula

$$
\mathrm{n}=\mathrm{n}=\underset{\substack{\mathrm{N} \\ 1+\mathrm{N}(\mathrm{e})^{2}}}{156694}
$$




\section{$\overline{1+156694(0.05)^{2}}$

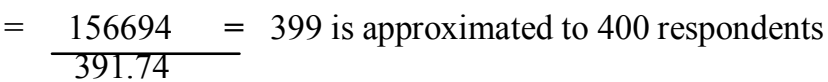

Where $\mathrm{N}$ is target population, $\mathrm{n}$ is sample size and e is level of significant and is constant $(0.05)$

Instrument for Data Collection: Data was collected by giving questionnaires that was developed by the researcher and subjected to scrutiny by experts in the field of Nursing, Education, Psychology, Sociology and Demography. Section A of the questionnaire was to elicit the socio demographic data of the respondent and consist of eight questions while Section B consist of about twenty-three questions that elicit information on; knowledge about contraception, parents influence on adolescents sexuality and contraception, best method(s) of contraception for adolescents, parents attitudes toward contraceptives for adolescents and factors that influence parents attitudes on adolescents contraception

\section{Ethical Consideration and Permission to Conduct the Study}

Letters of introduction was given to the community leaders in charge of the selected areas and verbal approval was granted by them. Each respondent was informed verbally on the aim of the study, they were assured of their anonymity and confidentiality of information when analyzing the data and discussing the findings. Verbal positive response was given by the participants. Their right to participate or not was duly respected.

\section{Validity and Reliability of the Instrument}

Questionnaire was constructed and presented to the scholars in the field of Nursing, Education, Sociology and Psychology to establish face and content validity. Pilot study was conducted using test and re-test method to determine the reliability of the instrument. Ten selected parents who were not part of the study were given same questions at two weeks intervals. The correlation co-efficient was calculated to be 0.78 .

\section{Results}

This section presents the analysis of results of the research work.

TABLE 4.1: Socio demographic characteristics of the respondents.

\begin{tabular}{|c|c|c|c|}
\hline Variable & Levels & Frequency $(\mathrm{N}=400)$ & Percentage (\%) \\
\hline Age & $\begin{array}{l}20-30 \text { years } \\
31-40 \\
41-50 \\
50 \text { and above }\end{array}$ & $\begin{array}{l}44 \\
144 \\
139 \\
73\end{array}$ & $\begin{array}{l}11.0 \\
36.0 \\
34.8 \\
18.3\end{array}$ \\
\hline Sex & $\begin{array}{l}\text { Female } \\
\text { Male }\end{array}$ & $\begin{array}{l}261 \\
139\end{array}$ & $\begin{array}{l}65.2 \\
34.8\end{array}$ \\
\hline Marital Status & $\begin{array}{l}\text { Married } \\
\text { Single parent } \\
\text { Divorced } \\
\text { Widow }\end{array}$ & $\begin{array}{l}360 \\
31 \\
6 \\
3\end{array}$ & $\begin{array}{l}90.0 \\
7.8 \\
1.5 \\
0.7\end{array}$ \\
\hline Duration of your marriage & $\begin{array}{l}1-10 \\
11-20 \\
21-30 \\
31-40\end{array}$ & $\begin{array}{l}126 \\
130 \\
120 \\
24\end{array}$ & $\begin{array}{l}31.5 \\
32.5 \\
30.0 \\
6.0\end{array}$ \\
\hline Occupation & $\begin{array}{l}\text { Civil Servant } \\
\text { Artisan } \\
\text { Farmer }\end{array}$ & $\begin{array}{l}340 \\
72 \\
8\end{array}$ & $\begin{array}{l}85.0 \\
13.0 \\
2.0\end{array}$ \\
\hline Education Qualification & $\begin{array}{l}\text { Primary } \\
\text { Secondary } \\
\text { Tertiary } \\
\text { Other }\end{array}$ & $\begin{array}{l}88 \\
39 \\
249 \\
24\end{array}$ & $\begin{array}{l}22.0 \\
9.7 \\
62.3 \\
6.0\end{array}$ \\
\hline Religion & $\begin{array}{l}\text { Christianity } \\
\text { Islam }\end{array}$ & $\begin{array}{l}290 \\
110\end{array}$ & $\begin{array}{l}72.5 \\
27.5\end{array}$ \\
\hline Ethnicity & $\begin{array}{l}\text { Yoruba } \\
\text { Igbo } \\
\text { Hausa }\end{array}$ & $\begin{array}{l}331 \\
40 \\
29\end{array}$ & $\begin{array}{l}82.7 \\
10.0 \\
7.3\end{array}$ \\
\hline
\end{tabular}

Table 4.1 above showed that $36.0 \%$ of the respondents were within the age range of 31 and 40 years. Also more than half $(65.0 \%)$ of the respondents were female and almost all $(90 \%)$ the respondents were married. 
Parental Attitude towards the use of Contraceptives by Adolescents in Osogbo,Osun State.

Also $32.5 \%$ of the respondents were within the range of 11 and 20 years in marriage. In addition, $85.0 \%$ of the respondents were civil servants. Moreover, two hundred and fifty-nine $(62.3 \%)$ of the respondents attended tertiary institutions. According to the religion inclination $72.5 \%$ of them were Christian and a larger percentage of the respondents $(82.7 \%)$ were Yorubas.

Table 4.2: Parental Knowledge and Attitudes on Adolescents Contracepton

\begin{tabular}{|l|l|l|}
\hline \multicolumn{1}{|c|}{ VARIABLES KNOWLEDGE } & \multicolumn{1}{l|}{ FREQUENCY } & \multicolumn{1}{l|}{ PERCENTAGE } \\
\hline Good Knowledge & 277 & 12.5 \\
\hline Moderate Knowledge & 50 & 18.2 \\
\hline Poor Knowledge & 73 & 100 \\
\hline Total ATTITUDE & 400 & 16.3 \\
\hline \multicolumn{1}{|c|}{} & 14.2 \\
\hline Positive Attitude & 65 & 69.5 \\
\hline Negative Attitude & 57 & 100 \\
\hline Very Negative Attitude & 278 & \\
\hline Total & 400 & \\
\hline
\end{tabular}

From the table above, it can be seen that greater percentage of the respondents $69.3 \%$ had good knowledge about contraception and larger percentage of the respondents $(69.5 \%)$ had very negative attitude toward provision of contraceptive to adolescents.

Table 4.3: Methods of Contraception Prefer by Parents for Adolescents

\begin{tabular}{|l|l|l|}
\hline \multicolumn{1}{|c|}{ VARIABLE } & FREQUENCY & PERCENTAGE \\
\hline Total abstinence & 337 & 84.2 \\
\hline Use of condoms & 31 & 7.8 \\
\hline Inter-uterine device & 16 & 4.0 \\
\hline Safe period device & 16 & 4.0 \\
\hline Total & 400 & 100 \\
\hline
\end{tabular}

From this table, it can be seen that majority of the respondents $(84.2 \%)$ believed that total abstinence is the method that they can choose for their adolescent.

Testing of Hypotheses

Hypothesis One: There is no significant relationship between gender and attitudes toward the use of contraceptives by Adolescents among parents/respondents

Table 4.4: Pearson Correlation Analysis on gender and parental attitudes towards use of contraceptives by adolescents.

\begin{tabular}{|c|c|c|c|c|c|c|c|}
\hline Variable & $\overline{\mathrm{N}}$ & Mean & SD & $\overline{\mathrm{Df}}$ & $\mathrm{r}^{\text {-cal }}$ & $\mathrm{r}^{\text {-tab }}$ & $\begin{array}{l}\mathrm{P}^{\text {-val }} \\
0.05\end{array}$ \\
\hline Sex & 400 & 1.347 & 0.477 & & & & \\
\hline & & & & 398 & 0.572 & 0.098 & $<0.05$ \\
\hline Parental attitudes & 400 & 1.277 & 0.722 & & & & \\
\hline
\end{tabular}

Table 4.4 shows the Pearson's correlation coefficient statistics that was produced to show the relationship between the gender and parental attitudes $\left[\mathrm{r}^{-\mathrm{cal}}=(0.272), \mathrm{r}^{\text {-tab }}=(0.098), \mathrm{P}^{\text {-val }}<(0.05)\right]$, which is significant at P 0.05 level (2 tailed). Since r-calculated is greater than r-tabulated. The null hypothesis was hereby rejected and alternative hypothesis was considered. Thus there is a significant difference between gender and parental attitudes towards the use of contraceptives by adolescents.

\section{Hypothesis Two}

There is no significant relationship between religious belief of the parents and their attitudes towards adolescent contraception usage.

Table 4.5: Pearson Correlation Analysis on religious belief of the parents and their attitudes towards adolescent contraception. 
Parental Attitude towards the use of Contraceptives by Adolescents in Osogbo, Osun State.

\begin{tabular}{|c|c|c|c|c|c|c|c|}
\hline Variable & $\bar{N}$ & Mean & SD & $\overline{\mathrm{Df}}$ & $\mathrm{r}^{\text {-cal }}$ & $\mathrm{r}^{\text {tab }}$ & $\mathrm{P}^{\text {-val }} 0.05$ \\
\hline Religious belief & 400 & 1.275 & 0.447 & & & & \\
\hline & & & & 398 & 0.429 & 0.098 & $<0.05$ \\
\hline $\begin{array}{l}\text { attitudes towards } \\
\text { adolescent contraception }\end{array}$ & 120 & 1.277 & 0.722 & & & & \\
\hline
\end{tabular}

Table 4.6 shows the Pearson's correlation coefficient statistics that was produced to show the relationship between religious belief and parental attitudes towards adolescents' contraception. $\left[\mathrm{r}^{\text {-cal }}=(0.229)\right.$, $\left.\mathrm{r}^{\text {tab }}=(0.098), \mathrm{P}^{\text {-val }}<(0.05)\right]$, which is significant at $\mathrm{P} 0.05$ level $(2$ tailed). Since $\mathrm{r}$-calculated is greater than $\mathrm{r}-$ tabulated, the null hypothesis was rejected and thus there is a significant relationship between religious belief and parental attitudes towards adolescents' contraception.

\section{Discussion}

This study assessed the attitude of parents in Osogbo towards administration of contraceptives to adolescent. The result showed that less than half of the respondents (36.0\%) were within the age range of 31 and 40 years, this is contrary to study conducted by Forge (2003) that discovered that people enter marriage as early as 25 years of age. . Also more than half $(65.2 \%)$ of the respondents were female, this supported the study conducted by Ladapo (2004) that female parents are significantly more than male parents. Also it was observed that (90\%) were married, this buttressed the finding of David (2006) that married parents outweigh the single parents in Nigeria. Also less than half of the respondents (32.5\%) were within the range of 11 and 20 years in marriage. In addition, majority of the respondents $(85.0 \%)$ were civil servants, this reinforced the finding of study conducted by Awodele et al (2008) that majority of parents in Osogbo are civil servants. Moreover, a higher percentage of the respondents $(62.3 \%)$ had tertiary education as their educational qualification. According to the population distributions on religion (72.5\%) of them were Christian and this is contrary to findings of Awodele (2008) that said Muslim are more in Osogbo than Christians. Larger percentages of the respondents $(82.7 \%)$ were Yorubas. This is in line with a study conducted by Olawuni (2007) in Osogbo that majority of Osogbo dwellers are Yorubas.

The findings showed that more than half of the parents had good knowledge about contraception as $70.3 \%$ of them agreed strongly that it is a method adopted to prevent pregnancy. Above $60 \%$ of the parents agreed that contraceptives is not meant for those that have completed their family alone. Less than half $(46.7 \%)$ of the respondents agree that contraceptives leads to improved health among the adolescents and this is in accord with Foege (2008) that said family planning is part of preventive medicine and an important service leading to improved health. One of the aims of family planning is to reduce the problems that arise from adolescent's pregnancy. Findings from the study showed that $69.3 \%$ of the respondents had negative attitude toward provision of contraception to adolescents. This is in contrary to WHO (2004) which says that Adolescent fertility regulation and pregnancy prevention is one of the most important health-care issues of the twenty-first century.

The findings also reveal that a greater percentage $(69.5 \%)$ of the parents has high influence on adolescents' sexuality and contraception. This is in line with earlier studies by Fasula \& Miller, Pearson, Muller, \& Frisco,( 2006) that said Parent-adolescent communication and parent responsiveness to sexual discussions play an important role in delaying early sexual intercourse and this is especially true for girls. The study conducted by Miller, \& Hummert, (2002)also revealed that "healthy" family communication is a key indicator of whether an adolescent will engage in high-risk behaviours .Finding from the study further showed that $80 \%$ of the parents disagree on introduction of contraception to adolescents .

It can also be deduced from the findings that greater number (84.2\%) of the parents will encourage total abstinence for adolescents as a method of contraception however study conducted by Kirby (2008) showed that the policy toward abstinence in the U.S. has not been successful. It further showed that most abstinence programs did not delay initiation of sex neither have any significant positive effects on any sexual behaviour.

Santelli et al. (2006) reported that although abstinence from sexual intercourse is a healthy choice for adolescents, "abstinence only" as a single option is flawed. This means that total abstinence alone cannot be effective based on trend of civilization and modernization. Dangal, (2006) reported that approximately onefourth of adolescents have reported they had intercourse prior to age 15 and despite the number of safe, effective contraceptive methods available, pregnancy among teenagers is still prevalent.

Aquilino \& Bragadottir, (2000) stated that consistent high rates of adolescent pregnancies in the U.S. continue to generate public concern because adolescent pregnancy has been associated with adverse health and social consequences. Adolescent mothers, particularly those under 17 years of age, are more likely to have truncated education, lower-paying jobs, higher levels of unemployment, larger families with close spacing of children, a higher likelihood of marital disruption, future out-of-wedlock pregnancies, low birth weight babies, and poverty status. 
Glei, (1999) stated that although access to initiating contraception for adolescents has increased, adolescents are erratic contraceptors because they do not use contraception consistently and with nearly one million teenage pregnancies occurring each year in the U.S, an understanding of adolescents' decision making in contraceptive use is one of the first steps toward creating solutions for this problem. Although there are pros and cons from various research studies on the subject of abstinence, many adolescents are sexually active, and contraception remains a significant part of the national effort to reduce adolescent pregnancy.

\section{Summary}

This study examined the attitude of parents toward administration of contraceptives to adolescent in Osogbo. It further asses the level of parents' knowledge about contraceptives and attitude of parents toward providing contraceptives to adolescents. It also finds out the appropriate method (s) of contraception that parents prefer for adolescents

A descriptive design was adopted and four hundred parents were selected using a multi-stage sampling technique. Relevant data were collected using validated questionnaire (correlation co-efficient 0.78 ) that was constructed and presented to the supervisor and other scholars in the field of Nursing, Education, Sociology and Psychology to establish face and content validity. Data were analyzed using Pearson correlation coefficient.

The result of the study showed that parents had good knowledge about contraception and that they also had negative attitude towards adolescents' contraception. It was also discovered from the study that parents prefer total abstinence as best method of contraception for adolescents. The results showed that; there is significant influence of sex on the use of contraceptive devices by adolescents, there is significant relationship between the use of contraceptive devices and adolescent sexuality problem and there is significant influence of religion on parents' acceptance of contraceptive use among adolescents.

\section{Implications of Study}

The findings of this study had shown that parents had comprehensive understanding of what Adolescent contraception means. The result of the study implied that parents did not support the use of contraceptives among adolescents in Osogbo and this can subsequently increase the rate of teenage pregnancy and other associated problems. Therefore, there is need for educative programmes for parents in order to let them know the importance of contraceptives among adolescents.

\section{Recommendations}

There is need for educative programmes on adolescent contraception for parents in osogbo.

Family planning services should incorporate facilities for adolescents where teenagers requiring sexual and reproductive health services will have access to good quality information, advice on contraceptives and guaranteed confidentiality.

There is also need for education of adolescents on utilization of contraceptives.

Further research should be carried out where adolescents themselves will be involved so that their perception and interest will be known.

Moreover, other variables should also be put into considerations as these may have moderating roles on the outcome of the findings. Any researcher that wants to carry out relevant study should endeavour to use larger samples which comprises of both parents and adolescents.

\section{Acknowledgement}

All honour and adoration is returned to Almighty God for giving me the sufficient grace and for sparing my life to see the completion of this research project.

My undiluted appreciation goes to my mentors Dr B.L Ajibade and Mr. Joel Faronbi for their supervision, patience, corrections and guidance during the course of writing this project. My sincere prayer is that God Almighty will increase your knowledge and enlarge your territory.

My heartfelt appreciation also goes to the members of my nuclear family; my wife, and my children for giving me the enabling environment to complete this study.It is my prayer that our home will be source of joy and happiness to our generation and we shall live long to reap the fruit of our labour.

I also wish to acknowledge the support and encouragement of my brother, Chief Oyewale Oyediran and my uncle, Dr. Adigun Oyetayo. I pray that God will continue to uphold you.

In addition, I wish to appreciate the parents of the selected areas in Osogbo for sparing their time in filling and responding to the questionnaires. God, the merciful will never leave them alone in time of needs.

Finally, I want to appreciate all the Perioperative Nurses of Ladoke Akintola University of Technology Teaching Hospital, Osogbo for their support and encouragement throughout the period of carrying out this research. 
I say a big thank you and God bless to all other persons too numerous to mention who have contributed to the success of this project.

\section{References}

[1] Amazizo, U, et.al (2004), "Sexual activity and contraceptive knowledge and use among in school adolescents in Nigeria". International Family Planning Perspective. Vol. 28, 28 - 33.

[2] Aronson, E. (1991) “The cognitive Dissonance theory”. Journal of Abnormal and social Psychology.Vol 30 , No 21

[3] Awodele, K. (2008) "Knowledge, Attitude and Practice of premarital sexual intercourse among school Adolescents in Osogbo Local Government Area, Osun State.” African Journal of Reproductive Health $2009 ; 12$ : 150 - 165.

[4] Caparalo. F.K. (2005): "Sexual Health, Needs of the mentally retarded adolescent Female”. Issues health care. Vol. 335 - 46.

[5] Caroline, C (2004), “Adolescent Contraception" Journal of Adolescent health.Vol.22, No 6 May/June

[6] David, M. (2006): “Adolescent sexual Awareness, knowledge, Attitudes and behavior studies”. Family Planning Journal Vol. 5, No. 3 May/June.

[7] Douglas, N.L \& Otolorin E. (2006), "Sexual behavior contraceptive practice and Reproductive health among Nigeria Adolescents" "Studies in Family Planning Vol. 19, No. 2. March/April.

[8] Foege, W.H (2003): "Family Planning methods and Practice: Atlanta Georgia US.A ; Africa Center for disease control for health promotion and education.

[9] Kathleen, A. C. (2010) Parental influence on Adolescent Decision making and Contraceptive use. Journal of Paediatric Nursing. Vol 4 June/July.

[10] Olawuni P.O (2007) Journal of land use and development studies. vol no 1,pg 149.

[11] Hotmann, A.D. (2004) "Contraception in Adolescents: A Revenue psychosocial aspects" Bulletin of the World Health Organization.

[12] Nicholas, D. et al (2005). "Sexual behavior contraceptive and Reproductive health among Nigeria Adolescents". Studies in Family Planning.

[13] Townsend J.W \& May D. (2007). Sex education and Family Planning services for Youth Adults", Hotman: Studies in Family Planning. Vol. 18, No. 2., March/April 